\section{Pre-deployment Cognitive Testing}

Nicholas David Smith

Educational and Psychological Studies, University of South Florida/ TBI Model Systems, James A. Haley VA Hospital, Tampa, FL, USA

\section{Also See}

$\rightarrow$ ANAM

- Battlefield Assessment

\title{
References
}

Pre-deployment Cognitive Testing: All service members are required to complete cognitive assessment 12 months prior to all deployments (Twille et al. 2012). Assessments of attention, memory, decision-making abilities, concentration, reaction time, and processing speed are typically completed (Sørensen et al. 2016). These tests establish an individual baseline in the event a service member is injured. When a service member is injured, post-deployment scores are compared to pre-deployment tests scores or population normative data to inform treatment decision-making (Thompson and Gottesman 2008).

Sørensen, H. J., Andersen, S. B., Karstoft, K. I., \& Madsen, T. (2016). The influence of pre-deployment cognitive ability on post-traumatic stress disorder symptoms and trajectories: The Danish USPER follow-up study of Afghanistan veterans. Journal of Affective Disorders, 196, 148-153.

Thompson, W. W., \& Gottesman, I. I. (2008). Challenging the conclusion that lower preinduction cognitive ability increases risk for combat-related post-traumatic stress disorder in 2,375 combat-exposed, Vietnam war veterans. Military Medicine, 173(6), 576-582.

Twillie, D. A., Logan, B. W., \& Grate, S. J. (2012). Effects of military deployment on cognitive functioning. Military Medicine, 177(3), 248. 